Rev. Medicina Desportiva informa, 2020; 11(6):11-21 https://doi.org/10.23911/Dossier frio 2020 nov

\section{Praticar exercício físico em ambiente frio}

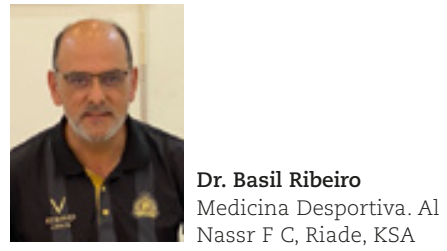

Introdução

A prática de exercício físico em condições atmosféricas adversas (excesso de calor ou de frio, de vento ou de humidade, sob chuva) exige do corpo humano adaptações permanentes no sentido de manter a homeostasia interna e o rendimento desportivo desejado. O desafio ao corpo humano aumenta ainda com a altitude muito elevada e no que se refere ao ambiente frio é diferente se desporto é praticado dentro ou fora de água. A exposição solar, o vestuário e a taxa metabólica são outros fatores que poderão interferir no aquecimento ou no arrefecimento excessivos. ${ }^{1}$

Em ambiente frio, a perda de calor por convecção é determinante para a hipotermia e queimadura pelo frio, que será maior na natação e proporcional à velocidade de nado e à diferença de temperaturas, pelo que a natação em águas abertas merece atenção especial. ${ }^{1}$ A Federação Internacional de Natação só permite a prova se a temperatura for superior a $16^{\circ} \mathrm{C}$, medida a $1 \mathrm{~m}$ de profundidade. Desde 2017 obriga ao uso de fatos de mergulho com temperatura da água inferior a $18^{\circ} \mathrm{C}$ e ao uso opcional se inferior a $20^{\circ} \mathrm{C}{ }^{2}$

No sentido de se avaliar a temperatura mínima da água para a prática de maratonas de natação, 12 nadadores de competição foram instruídos para nadaram com touca e calção, durante duas horas, em águas cuja temperatura variou entre 14 e $20^{\circ} \mathrm{C}$. A temperatura retal, a perceção ao esforço e o rendimento foram medidos. Com a água a $16^{\circ} \mathrm{C}$, seis nadadores não terminaram a prova
(4 ficaram ou previa-se que ficassem com hipotermia) e a $18^{\circ} \mathrm{C}$ quatro não terminaram, dos quais três ficaram ou previa-se que ficassem com hipotermia. Os autores concluíram que as temperaturas da água igual a 16 e a $18^{\circ} \mathrm{C}$ são demasiado baixas para a prática daquele tipo de provas. ${ }^{2}$

Para além do risco de hipotermia, a imersão em água fria, assim como a apneia, desencadearam reflexo autonómico, de que resultou bradicardia, ao passo que a imersão em água termo neutra não causou ( $\mathrm{p}<$ 0.01 e 0.002 , respetivamente), e a aplicação simultânea dos dois estímulos teve efeito cumulativo. ${ }^{3}$

Fora de água, o vento favorece a perda de calor por convecção, mas também o vestuário excessivo poderá provocar sudorese abundante, perdendo-se depois calor na evaporação desse suor. A quantidade de roupa e capacidade de reflexão do vento da peça exterior são fundamentais para a prevenção da hipotermia. ${ }^{1}$ A inalação do ar frio, para além de eventuais problemas respiratórios, causará arrefecimento adicional, pelo que em ambientes muito frios se aconselha a colocação de um lenço ou outra peça sobre a boca e nariz. O vestuário molhado que acontece quando o desporto é praticado sob chuva, habitualmente ela própria fria, favorece a convecção e a perda de calor. ${ }^{1,4,5} \mathrm{Com}$ velocidade elevada, como acontece no ciclismo, o risco de hipotermia é elevado, agravado pelo deficiente equipamento protetor.

Curiosamente, em desportos de inverno, poderá ser o staff de apoio o de maior risco para hipotermia, pois permanece durante bastante tempo, horas, a assistir e a dar apoio aos atletas, ao passo que estes realizam provas de curta duração, quase todas de duração inferior a três minutos, e com intensidade metabólica elevada, pelo que com elevada produção de calor interno. ${ }^{1}$

A permanência em pé de sete jovens saudáveis, durante 20 minutos, 1) sem chuva e sem vento, 2) expostos ao vento (3 m/s) e 3) expostos ao vento $(3 \mathrm{~m} / \mathrm{s})$ e à chuva $(40 \mathrm{~mm} / \mathrm{h})$ teve maior perda de calor em 3) comparado com as outras duas situações de análise $(p<0,01)$, com temperatura cutânea significativamente inferior. ${ }^{4}$ Foi realizado um estudo com 12 atletas $(21.7 \pm 3.3$ anos de idade; estatura $=1.76 \pm 0.08$ m; peso corporal: $68.8 \pm 7.1 \mathrm{~kg}$; $\left.\mathrm{VO}_{2} \max =67.3 \pm 5.0 \mathrm{~mL} / \mathrm{kg} / \mathrm{min}\right), \mathrm{em}$ tapete rolante (intensidade $=80 \%$ do $\mathrm{VO}_{2}$ max), durante 60 minutos, com chuva e sem chuva, num ambiente frio $\left(5^{\circ} \mathrm{C}\right) . .^{5}$ A temperatura retal, medida aos 10, 40, 50 e 60 minutos de prova, assim como a temperatura média cutânea, foram inferiores na prova sob chuva $\mathrm{p}<0,05)$. $\mathrm{OVO}_{2}$ e a perceção do esforço foram também superiores aos 50 e 60 minutos em relação à condição sem chuva. Os autores referem ainda que com o evoluir das provas a perda de calor intensificou-se devido à cada vez maior área molhada. ${ }^{5}$

O inverno aproxima-se, será frio e chuvoso, há prática de exercício físico e de desporto no exterior, o risco de hipotermia poderá ocorrer, especialmente nos amantes de desporto na neve, mas também nos que molhados e frios insistem em terminar o treino ou a competição. As consequências médicas negativas a nível respiratório e cardíaco poderão ocorrer, pelo que importa estar atento, assim como orientar as crianças e adolescentes nestes ambientes potencialmente adversos. Perceber a reação fisiológica do organismo ao frio e a utilização adequada do vestuário são elementos importantes para a prevenção da hipotermia.

\section{Bibliografia}

1. MF Bergeron et al. International Olympic Committee consensus statement on thermoregulatory and altitude challenges for high-level athletes. 2012 Sep; 46(11):770-9. Doi: 10.1136/bjsports-2012-091296

2. Jane Saycell et al. How cold is too cold? Establishing the minimum water temperature limits for marathon swim racing. Br J Sports Med. 2019 Sep; 53(17):1078-1084. doi: 10.1136/ bjsports-2018-099978.

3. N Marsh et al. Relative contributions of volun tary apnea, exposure to cold and face immersion in water to diving bradycardia in humans. Clin Exp Pharmacol Physiol. 1995 Nov; 22(11):886-7. doi: 10.1111/j.1440-1681.1995 tb01957.x.

4. Motoi Yamane et al. Effects of wind and rain on thermal responses of humans in a mildly cold environment. Eur J Appl Physiol. 2010 May; 109(1):117-23. doi: 10.1007/s00421-010-1369-y.

5. Ryo Ito et al. Rain exacerbates cold and metabolic strain during high-intensity running. Sports Med Phys Fitness. 2019 Oct; 59(10):1601-1607. doi: 10.23736/S00224707.19.09865-7 


\section{Termorregulação e impacto no rendimento}

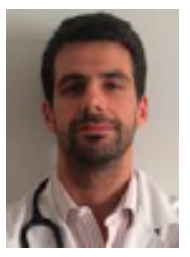

Dr. José Pedro Marques

Desportiva. Federação Portuguesa de Futebol; Hospital da Luz-Torres de Lisboa; SPMD

\section{Introdução}

O ser humano pode, em certa medida, ser visto como um animal tropical. A maioria dos ajustes feitos pelo organismo quando exposto a temperaturas elevadas é fisiológica. Ao invés, uma parte importante da resposta ao stress térmico imposto pelo frio é comportamental (exemplo: acrescentar camadas de roupa, procurar abrigo). Tal pode ser explicado pelo facto de a exposição a ambientes frios ser algo relativamente recente na história evolutiva dos hominídeos.

\section{Termorregulação}

A temperatura corporal é mantida em intervalos relativamente estreitos por um conjunto de mecanismos homeostáticos e comportamentais. A temperatura basal média é de cerca de $37^{\circ} \mathrm{C}$, com flutuações circadianas de até $1^{\circ} \mathrm{C}$. Existem sensores térmicos distribuídos pelo corpo, sobretudo na pele e SNC. Aqueles que veiculam informação sobre a temperatura central são os mais preponderantes na resposta termorreguladora. A melhor forma de aferir a temperatura central é tema polémico na literatura científica. Vários locais são usados para a estimar - membrana timpânica, estômago, reto, esófago e axila. Os mais práticos (axila, ouvido) são tendencialmente menos fiáveis, com frequência subestimando a temperatura. Os outros são de difícil aplicação no terreno. O clínico que avalia atletas com hipotermia deve ter estas limitações em mente.

Quando a temperatura ambiente desce abaixo dos $28^{\circ} \mathrm{C}$, o corpo humano tem de diminuir as perdas de calor e/ou aumentar a sua produção. Este stress térmico desencadeia uma resposta do SN simpático, otimizando o isolamento térmico via vasoconstrição do leito cutâneo. Quando esta resposta se revela insuficiente (ex: temperaturas mais baixas, exposição mais duradoura) a termogénese é promovida - inicialmente via aumento do metabolismo basal e, eventualmente, através do desencadear das contrações musculares involuntárias típicas dos arrepios de frio. O exercício físico contribui também para um significativo aumento do metabolismo e, consequentemente, da produção de calor.

As perdas de calor são, em grande medida, função do gradiente térmico entre a pele e o meio ambiente. Há, no entanto, outros fatores a considerar nesta equação. No que respeita ao atleta:

- Uma maior percentagem de massa gorda contribui para um isolamento térmico mais eficaz;

- Uma maior área de superfície corporal indexada ao peso está associada a taxas inferiores de perda de calor;

- Maior massa muscular ativa traduz-se em maior produção de calor.

Isto explica o risco aumentado de hipotermia em crianças e idosos. As diferenças entre sexos quanto à tolerância ao frio serão mínimas, pois se por um lado as mulheres têm tendencialmente melhor isolamento térmico (maior percentagem de massa gorda), por outro os homens têm habitualmente maiores massas musculares ativas.

No que concerne ao ambiente, o vento aumenta significativamente as perdas de calor por convecção. Tal justifica que, para a mesma temperatura, o potencial de arrefecimento do ambiente (e risco de hipotermia) seja superior em condições ventosas. A temperatura ambiente e o vento combinam-se para formar o wind chill index.

No exercício em meio aquático importa referir que a condutividade térmica da água é bastante superior à do ar. Como tal, o corpo humano perde calor quatro vezes mais rapidamente dentro que fora de água. A taxa de perda de calor pode ainda ser acelerada (via convecção) pelo movimento da água ao redor do atleta.

\section{Resposta ao exercício no frio}

A exposição ao frio aumenta o risco de desidratação. Fá-lo sobretudo por:

- indução da vasoconstrição periférica, que ao condicionar o aumento do fluxo sanguíneo renal provoca a diurese fria;

- hiperventilação, com aumento das perdas insensíveis (especialmente se o ar for seco);

- atenuação da sede.

A ingestão de diuréticos (exemplo: cafeína, bebidas alcoólicas) antes/ durante o exercício e a disponibilidade de água devem ser tidos em conta.

A nível cardíaco, o frio condiciona diminuição da frequência cardíaca, depressão miocárdica e alterações da condutividade elétrica. A função neuromuscular pode ficar comprometida. O frio atrasa a condução dos impulsos nervosos e a transmissão neuromuscular, podendo provocar parestesias, descoordenação motora e alterações cognitivas. As baixas temperaturas associam-se ainda a fraqueza e rigidez muscular, o que releva a importância do aquecimento e alongamentos adequados nestas condições. Os arrepios de frio (shivering) podem também comprometer o controlo neuromuscular. Quanto à utilização de substratos energéticos realça-se que, apesar da libertação de catecolaminas promover a mobilização e utilização de ácidos gordos livres, esta resposta é de algum modo atenuada pela vasoconstrição que afeta as reservas periféricas de gordura. Daí resulta um aumento na dependência do glicogénio muscular.

O aumento do metabolismo durante o exercício e o isolamento térmico conferido por vestuário adequado são, na maioria dos atletas e das condições que estes encontram em provas, suficientes para mitigar a diminuição da performance e diminuir o risco de lesões provocadas pelo frio. É nas provas de mais longa duração que tais riscos são mais prementes. A instalação da fadiga diminui a intensidade a que o atleta se consegue exercitar e, por consequência, a produção de calor. A função neuromuscular é afetada quando a temperatura do músculo desce abaixo dos $27^{\circ} \mathrm{C}$. Tal acarreta a diminuição da eficiência mecânica do movimento e o aumento do custo energético para um esforço 
submáximo. Juntamente com a progressiva depleção das reservas energéticas, estes são importantes fatores que conduzem ao encurtamento do tempo até à fadiga. É com a instalação desta que o risco de hipotermia e lesões causadas pelo frio aumenta significativamente.

\section{Aclimatação}

A evidência existente nesta área é ainda parca e contraditória, pelo que a existência de uma verdadeira aclimatação ao frio é objeto de amplo debate na literatura. Young et al propõe a existência de três padrões de aclimatação naqueles que são expostos regularmente a estas condições:

- a habituação, caracterizada por atenuação das respostas fisiológicas habituais ao frio;

- a aclimatação metabólica, caracterizada pelo incremento da termogénese;

- a aclimatação por isolamento, via promoção dos mecanismos que conservam calor.

\section{Bibliografia}

1. Brukner P, Khan K et al. Brukner \& Khan's Clinical Sports Medicine (Volume 2). $5^{\text {th }}$ ed. New South Wales: McGraw-Hill Education Australia, 2019.

2. Kenney WL, Wilmore JH, Costill DL. Physiology of Sport and Exercise. 6th ed. Human kinetics, 2015.

3. Castellani JW, Young AJ. Human physiological responses to cold exposure: Acute responses and acclimatization to prolonged exposure. Autonomic Neuroscience. 2016; 196:63-74.

\section{Exercício em clima frio em idade pediátrica}

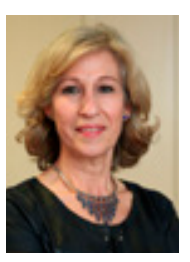

Prof. Doutora Carla Rêgo Pediatra no Hospital CUF Porto. Professora Auxiliar da Faculdade de Medicina da Universidade do Porto. Professora Convidada da ESBUniversidade Católica Portuguesa. Investigadora do Pro-Nutri do CINTESIS

O exercício realizado em ambiente frio induz um aumento da termogénese, tendo em vista a prevenção do arrefecimento corporal excessivo.

A criança emprega estratégias termorreguadoras diferentes do adulto, na dependência de diferenças anatómicas, fisiológicas e psicológicas. Tem uma razão superfície-massa corporal mais elevada, menor taxa de sudação, maior vascularização periférica no calor (por vasodilatação) e maior vasoconstrição no frio, resultando na menor velocidade de aclimatização comparativamente ao adulto. Também é diferente a sua percepção do risco, na dependência da menor experiência e capacidade decisória, resultantes do seu desenvolvimento cognitivo.

Efetivamente, quer numa perspetiva psicológica / comportamental, quer especialmente numa prespetiva meramente biológica, ao se comportar de forma particular na regulação térmica, a criança está em desvantagem relativamente ao adulto no que respeita ao controlo da temperatura corporal em ambiente frio, tendo em conta dois fatores: maior superfície corporal e menor panícula adiposa subcutânea. A velocidade da perda de calor corporal (via convexão, condução e radiação) depende da superficie corporal (SC) e, quanto mais pequeno é o indivíduo, maior é a SC por unidade de massa corporal, estando pois a velocidade de arrefecimento corporal inversamente correlacionada com a idade. No que respeita à panícula adiposa, a gordura é um verdadeiro isolador térmico, pelo que quanto mais espessa é a adiposidade subcutânea, maior a preservação da temperatura corporal, particularmente em meio aquático. Esse facto torna-se relevante quando, como referido, a vascularizaçao cutânea decresce com o exercício, reduzindo a convecção do calor corporal para a periferia, sendo então a velocidade da perda de calor corporal limitada pela lentificação da condução através da lâmina de tecido gordo subcutâneo.

Existem efeitos deletérios da prática de exercício por crianças / adolescentes em ambiente frio que importa conhecer, mas sobretudo evitar: a hipotermia, a queimadura pelo frio e a broncoconstrição.

\section{Hipotermia}

As crianças/adolescentes mais suscetíveis a hipotermia são as desnutridas, quer por baixo peso constitucional, quer consequente a patologia (ex: fibrose cística, anorexia nervosa, etc). Frequentemente, são crianças mais pequenas, pelo que apresentam maior SC, à qual acresce a reduzida lâmina de panícula adiposa subcutânea. Outro grupo vulnerável, particularmente em desportos na água, são as crianças com baixa estatura (frequentemente constitucional), por apresentarem uma elevada razão SC/massa corporal. Em desportos de elevada intensidade de produção de calor e consequentemente de sudação (ex: hóquei no gelo), deve ser chamada a atenção para o risco de hipotermia durante os períodos de descanso/ intervalo, caso não se proceda ao adequado aquecimento corporal.

\section{Atuação}

1- Desporto ao ar livre:

a) avaliar as caracteristicas do tempo; usar camadas de roupa seca e confortável (sintética, de polietileno, em contacto com a pele e nunca de algodão; depois, uma ou várias peças de lã e, finalmente, um impermeável), as quais serão retiradas ou usadas conforme a necessidade;

b) deve ser dada particular proteção aos dedos das mãos e aos pés. Quando o fator de arrefecimento resultante do vento for de 15-20 graus $^{\circ}$ ou inferior, a criança deve usar também proteção facial.

\section{2- Desporto na água (natação):}

a) sempre que possível, a temperatura da água deve ser $1-2^{\circ}$ superior à do adulto;

b) durante o treino a criança deve ser aconselhada a sair da água cada 15-20 minutos, particularmente as mais jovens e as com menor índice de massa corporal. Devem aproveitar estas paragens para garantir uma adequada hidratação oral;

c) Os nadadores em águas frias devem aplicar em toda a superficie corporal uma camada fina (1-2 mm) de lanolina ou um óleo corporal.

\section{Queimadura pelo frio}

São mais frequentes em áreas expostas (particularmente na região 
dos músculos masseteres, queixo, nariz e orelhas), mas também podem ocorrer em áreas cobertas, particularmete nas pontas dos dedos das mãos, nos dedos dos pés, mamilos e nos genitais masculinos. A suscetibilidade é variável entre indivíduos. Muito embora não existam dados epidemiologicos em idade pediátrica, a rápida vasoconstrição periferica que ocorre como resposta ao frio poderá sugerir maior risco, diretamente proporcional à menor idade da criança.

\section{Atuação}

a) utilizar várias camadas de roupa;

b) utilizar protetor solar;

c) hidratar regularmente;

d) estar atento a sinais de alarme (sonolência, lentificação de voz, descoordenação motora).

\section{Broncoconstrição}

Pode ocorrer particularmente em crianças / adolescentes com asma. A inalação de ar frio aumenta a perda de calor pela respiração, que é um fator desencadeante da broncoconstrição durante o exercico.

\section{Atuação}

a) a boca e nariz devem ser protegidos com uma máscara cirúrgica ou um cachecol, caso a temperatura ambiente seja igual ou inferior a $10^{\circ} \mathrm{C}$. Efetivamente, em exercicios de recreação ou de baixa intensidade, o facto da respiração ser predominantemente nasal permite o aquecimento e a humidificação do ar inspirado. No entanto, com o aumento da intensidade e duração do exercício, a respiração torna-se predominantemente bucal, deixando de existir este mecanismo fisiológico de aquecimento / humidificação do ar inspirado. O uso de máscara cirúrgica ou cachecol permitirá criar uma bolsa de ar, tornando o ar inspirado mais húmido e quente;

b) as crianças com asma devem ser aconselhadas, em dias mais frios, a reduzir a intensidade dos exercícios no exterior.

Em conclusão, as catacterísticas termorreguladoras particulares da criança/adolescente, bem como a sua imaturidade psicológica e decisória, devem alertar para o maior risco de complicações na dependência da prática desportiva em ambiente frio. A avaliação cuidadosa das condições ambientais e das características somáticas e cognitivas da criança/adolescente devem definir e fazer antecipar as medidas de prevenção a tomar, não muito diferentes das do adulto.

\section{Bibliografia}

1. Bar-Or O. Children`s responses to exercise in cold climates: health implications. Sport Science Exchange. 1994; 7(4):chap 51.

2. Armstrong N, McManus AM (eds): The elite young athlete. Med Sport Sci. Basel, Karger 2011; 56:126-148.

3. Cappaert TA, Stone JA, Castellani JW, Krause BA, Smith D, Stephens BA. National Athletic Trainers Association Position Statment: environmental cold injuries. J Athlet Train. 2008; 43(6):640-58.

\section{Exercício em ambiente frio: particularidades na doença cardiovascular}

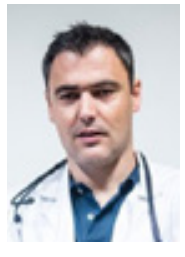

Prof. Doutor Hélder Dores Cardiologia. Hospital da Luz Lisboa; Human Performance Department - Sport Lisboa e Benfica; NOVA Medical School.

As respostas cardiovasculares (CV) à exposição ao frio em indivíduos saudáveis são conhecidas, mas na presença de algumas doenças CV estão menos clarificadas. Alguns mecanismos fisiopatológicos envolvidos tornam relevante a associação entre frio, exercício e doença CV. Várias análises têm revelado maior incidência de eventos CV nos meses mais frios do ano, incluindo enfarte agudo do miocárdio (EAM) e acidente vascular cerebral (AVC). Adicionalmente, quando realizado em ambiente frio, o exercício (sobretudo extremo) aumenta o risco destes eventos na presença de patologias, como doença das artérias coronárias (DAC) e insuficiência cardíaca (IC).
Apesar da intensidade e duração da exposição ao frio serem cruciais, há outros fatores a valorizar, tais como a presença de vento, altitude, imersão em água ou contacto com objetos frios. É ainda importante considerar características individuais, como a idade, género, estado nutricional e de hidratação, exposição prévia, condição física, antecedentes clínicos e medicação. Quando se analisa o impacto do frio na prática desportiva é também fundamental conhecer aspetos como a intensidade, aclimatação e condições em que é realizada (ex. proteção e vestuário utilizado).

A exposição ao frio influencia parâmetros CV, como frequência cardíaca (FC), volume de ejeção, resistência vascular periférica, pressão artéria (PA) e consumo miocárdico de oxigénio. Globalmente existem duas respostas homeostáticas: vasomotora para impedir a perda de calor, principalmente por vasoconstrição periférica, e metabólica para colmatar esta perda, como a termogénese por tremor muscular. Por outro lado, o exercício em ambiente frio aumenta a produção de calor, prevenindo a queda abrupta da temperatura corporal (estima-se que intensidade de 60\% do $\mathrm{VO}_{2}$ max pode prevenir hipotermia). Contudo, o efeito do exercício neste balanço térmico depende da interação complexa de vários fatores: se por um lado facilita a produção de calor, por outro contribui para a sua perda pelo aumento do fluxo sanguíneo na pele e músculos em atividade.

Embora a prática de exercício se associe a múltiplos benefícios e esteja recomendada em doenças CV crónicas, a exposição aguda ou prolongada ao frio pode ser prejudicial em determinados contextos clínicos. Entre os mecanismos associados à ocorrência de eventos CV pela exposição ao frio destacam-se o aumento da FC, PA, vasoconstrição periférica, concentração plasmática de fibrinogénio e viscosidade plaquetária. A estimulação do sistema nervoso simpático e as respostas hemodinâmicas ao stress também podem contribuir para esta morbi-mortalidade.

O aumento da resistência vascular periférica com maior necessidade miocárdica de $\mathrm{O}_{2}$, hiperatividade 
simpática e alterações vasomotoras da circulação coronária reduzem o limiar de isquemia durante a exposição ao frio. Estas respostas não têm um impacto relevante em indivíduos saudáveis, mas como o limiar de isquemia é alcançado mais cedo com a prática de exercício em ambiente frio, podem precipitar angina de peito na presença de DAC (estima-se em cerca de $40 \%$ dos doentes com DAC sintomática). A IC é muito heterogénea, tanto na etiologia como na apresentação clínica, partilhando alguns mecanismos também ativados pelo frio, que constituem mesmo alvos na sua abordagem terapêutica, mas que podem desta forma originar descompensação clínica. Além do risco clínico, o aumento do trabalho cardíaco com o frio diminui o rendimento e a capacidade física dos doentes com DAC e IC. A hiperestimulação simpática pela exposição ao frio também pode aumentar o risco de algumas arritmias.

O aumento da PA basal e a resposta pronunciada ao frio (alguns estudos revelam aumento de 5-30mmHg na PA sistólica e 5-15mmHg na diastólica), combinada com disfunção autonómica, podem comprometer a capacidade para o exercício e aumentar o risco em doentes hipertensos. O aumento da rigidez arterial com o frio é outro mecanismo responsável por esta resposta. Em conjunto, estas alterações podem aumentar o risco de AVC, tanto isquémico como hemorrágico. Além dos efeitos na PA, o frio eleva os valores da HbA1C, aumentando o risco em diabéticos.

Em suma, o exercício na doença CV deve ser incentivado, mas devidamente prescrito e individualizado. É essencial conhecer as suas características, nomeadamente o ambiente em que é realizado, porque a prática com temperaturas extremas, sobretudo na presença de algumas doenças, pode precipitar eventos clínicos graves.

\section{Asma e exercício em ambiente frio}

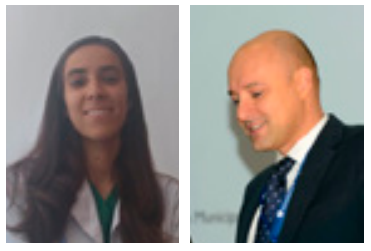

Dra. Mariana Bragança ${ }^{1}$, Prof. Doutor André Moreira ${ }^{1-3}$ ${ }^{1}$ Serviço de Imunoalergologia, Centro Hospitalar Universitário de São João; ${ }^{2}$ Imunologia Básica e Clínica, Departamento de Patologia, Faculdade de Medicina da Universidade do Porto; ${ }^{3}$ EPIUnit Instituto de Saúde Pública, Universidade do Porto.

A asma induzida pelo exercício (AIE) é definida pela presença de obstrução transitória das vias aéreas e sintomatologia de asma após a prática de exercício físico de elevada intensidade, em asmáticos. Esta apresentação clínica em indivíduos sem asma é denominada broncoconstrição induzida pelo exercício (BIE). ${ }^{1}$ A exposição a determinadas condições ambientais, como ar frio e/ou seco, alergénios, cloraminas de piscinas e a poluição atmosférica favorece a broncoconstrição durante a prática de exercício físico intenso e prolongado no tempo em indivíduos suscetíveis. ${ }^{2}$ Os atletas de endurance expostos a baixas temperaturas, durante os treinos/ competição, apresentam uma taxa de ventilação aumentada com inalação de grandes quantidades de ar frio e seco. Em resposta a esta exposição, consequência da humidificação e aquecimento do ar inalado, ocorre desidratação das vias áreas, com libertação de mediadores inflamatórios, e broncoconstrição através do reflexo parassimpático. À vasoconstrição inicial segue-se a hiperemia secundária que condiciona edema e agrava a obstrução brônquica. ${ }^{3}$

A exposição crónica ao ar frio e seco durante o exercício físico, nomeadamente em atletas de elite de desportos de inverno, condiciona lesão do epitélio respiratório e inflamação das vias aéreas, contribuindo para o desenvolvimento de AIE/BIE (Figura 1). Num estudo com atletas de cross country ski constatou-se que estes apresentam hiperreatividade brônquica (HRB) e sintomas de asma numa percentagem significativamente superior aos controlos, sendo que cerca de metade dos atletas estudados apresentavam AIE. ${ }^{4}$ Estudos posteriores comprovaram a maior prevalência de AIE/BIE em atletas de elite que praticam desportos de inverno e um risco nove vezes superior de desenvolver asma ocupacional em relação a outros desportos. A prevalência de asma nestes atletas aumenta com a idade dos atletas e a manutenção da prática desportiva. ${ }^{1,2}$

As manifestações de AIE/BIE em ambiente frio são as mesmas que noutro ambiente, com o surgimento de dispneia, pieira, aperto torácico e/ou tosse, geralmente, 5 a 30 minutos após exercício físico intenso. É expectável a regressão gradual e espontânea dos sintomas, sendo por vezes necessário recorrer a terapêutica de alívio. ${ }^{1}$ Contudo, após exercício em ambiente frio, esta recuperação pode ser atrasada se houver retorno acelerado a um ambiente quente, por exacerbação da desidratação da via aérea e edema por hiperemia secundária, com agravamento da broncoconstrição. ${ }^{5}$

Perante um atleta com sintomatologia sugestiva de AIE/BIE é necessário objetivar obstrução variável das vias aéreas através de espirometria com prova de broncodilatação [aumento do FEV1 superior a 12\% e $200 \mathrm{~mL}$ ] ou, caso esta seja normal ou duvidosa, HRB em testes de provocação brônquica. ${ }^{6}$ Os testes mais utilizados são provas de provocação com exercício (em campo ou no laboratório) e de hiperventilação voluntária eucápnica (EVH), cuja redução superior a 10\% do FEV1 determina positividade. Estes testes procuram mimetizar os grandes volumes de ar seco inalados durante a prática de exercício de endurance. Um estudo recente, comparou a EVH com um teste de ar frio (corrida de $5 \mathrm{~km}$ no exterior, a $-15^{\circ} \mathrm{C}$ ) e demonstrou que não há correlação entre estes testes e que a EVH pode não refletir a HRB decorrente do exercício em ambientes frios. ${ }^{5}$ Além destes, outros testes mais acessíveis na prática clínica podem ser utilizados, nomeadamente prova com metacolina ou com soluções hiperosmolares. ${ }^{7}$ Perante resultados negativos, é necessário procurar um diagnóstico alternativo para a sintomatologia do atleta. 


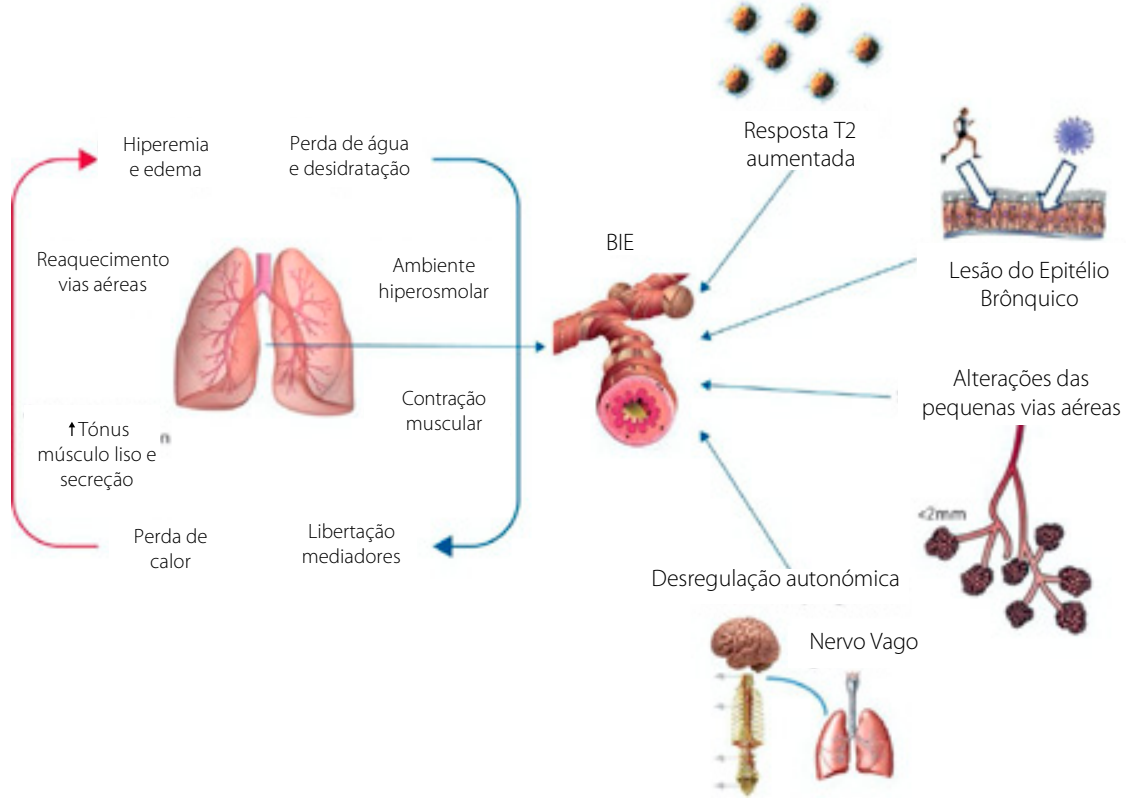

Figura 1 - Mecanismo fisiopatológico da Broncoconstrição Induzida pelo Exercício (BIE). Adaptado de Bonini, M. and O.S. Usmani, Let research leave you breathless, not physical exercise! ERJ Open Research, 2018; 4(1):00010-2018.

\begin{tabular}{|c|c|c|c|c|c|}
\hline & & & & \multirow{5}{*}{$\begin{array}{l}\text { Degrau } 4 \\
\text { Dose inter- } \\
\text { média ICS- } \\
\text { LABA }\end{array}$} & \multirow{5}{*}{$\begin{array}{l}\text { Degrau } 5 \\
\text { Alta dose CI - } \\
\text { LABA } \\
\text { Referenciar para } \\
\text { avaliação feno- } \\
\text { típica } \\
\pm \text { tratamento } \\
\text { add-on (tioprópio, } \\
\text { biológicos, ...) }\end{array}$} \\
\hline & & \multirow{4}{*}{$\begin{array}{l}\text { Degrau } 2 \\
\text { Baixa dose } \\
\text { CI ou baixa } \\
\text { dose ICS- } \\
\text { Formoterol } \\
\text { as-needed }\end{array}$} & \multirow{4}{*}{$\begin{array}{l}\text { Degrau } 3 \\
\text { Baixa dose } \\
\text { ICS- LABA }\end{array}$} & & \\
\hline & & & & & \\
\hline \multirow[b]{2}{*}{$\begin{array}{l}\text { Terapêutica } \\
\text { de manuten- } \\
\text { ção } \\
\text { (preferen- } \\
\text { cial) }\end{array}$} & & & & & \\
\hline & \begin{tabular}{|l|} 
Degrau 1 \\
Baixa dose \\
CI - For- \\
moterol \\
as-needed
\end{tabular} & & & & \\
\hline $\begin{array}{l}\text { Terapêutica } \\
\text { de alívio }\end{array}$ & \multicolumn{5}{|c|}{ Baixa dose CI - Formoterol as-needed (ou SABA as-needed) } \\
\hline
\end{tabular}

Figura 2 - Proposta de tratamento da asma. Adaptado das guidelines da GINA 2020. CI:

Corticoide Inalado; LABA: $\beta 2$ - agonista de longa ação; SABA: $\beta 2$ - agonista de curta ação

O tratamento dos atletas com AIE deve seguir as guidelines internacionais, nomeadamente as da GINA (Figura 2), com a particularidade que se deve assegurar que o código de antidopagem da World Anti-Doping Agency (WADA) é cumprido. Em relação aos $\beta 2$-agonistas, apenas são permitidos, por inalação, o salbutamol, formoterol e salmeterol, em doses terapêuticas. Os corticoides inalados são permitidos, contudo para os corticoides sistémicos é obrigatória a apresentação de uma escusa para uso terapêutico durante o período competitivo. Outros fármacos add-on, como os antagonistas dos recetores dos leucotrienos e anticolinérgicos, podem ser usados de acordo com as guidelines. ${ }^{8} \mathrm{~A}$ par da otimização terapêutica, é fundamental educar e empoderar os atletas, incluindo-os no processo de prescrição do plano de ação escrito. Durante os treinos em ambiente frio, os atletas devem usar máscara facial/gola, efetuar um bom aquecimento e respirar pelo nariz. E, dentro do possível, devem evitar treinar em condições extremas de temperatura e humidade. ${ }^{6}$

O ambiente frio é um trigger em indivíduos asmáticos e em atletas com exposição contínua e prolongada pode contribuir para o desenvolvimento de AIE/BIE. O conhecimento aprofundado da fisiopatologia desta entidade poderá contribuir para o tratamento mais personalizado e, eventualmente, para a identificação dos atletas com maior risco de desenvolverem asma ocupacional. Adicionalmente, mais estudos serão necessários para estabelecer o método mais indicado para diagnóstico de BIE em atletas com sintomas de asma desencadeados em ambiente frio.

Praticar exercício físico deve ser um prazer. O inverno aproxima-se e os atletas irão treinar em ambiente frio, quer por estarem no exterior, quer pelo mau isolamento característico dos pavilhões em Portugal. Não podendo controlar o ambiente de treino, é fundamental educar os doentes asmáticos para que controlem a sua doença e cumpram as medidas não farmacológicas. A equipa técnica, principalmente em desportos de inverno, deverá receber formação e estar alerta para os sintomas característicos de asma, referenciando os atletas precocemente.

\section{Bibliografia}

1. Carlsen, K.H., et al., Exercise-induced asthma, respiratory and allergic disorders in elite athletes: epidemiology, mechanisms and diagnosis: Part I of the report from the Joint Task Force of the European Respiratory Society (ERS) and the European Academy of Allergy and Clinical Immunology (EAACI) in cooperation with GA2LEN. Allergy, 2008; 63(4):387-403.

2. Couto, M., et al., Two distinct phenotypes of asthma in elite athletes identified by latent class analysis. The Journal of asthma : official journal of the Association for the Care of Asthma, 2015; 52(9):897-904.

3. Couto, M., et al., Exercise and airway injury in athletes. Acta Med Port, 2013; 26(1):56-60.

4. Larsson, K.O., P.; Larsson, L., et al, High prevalence of asthma in cross country skiers. British Medical Journal, 1993; 307:4.

5. Kennedy, M.D., et al., Cold air exercise screening for exercise induced bronchoconstriction in cold weather athletes. Respir Physiol Neurobiol, 2019. 269:103262.

6. Greiwe, J., et al., Work Group Report: Perspectives in Diagnosis and Management of Exercise-Induced Bronchoconstriction in Athletes. The Journal of Allergy and Clinical Immunology: In Practice, 2020; 8(8):25422555.

7. Fitch, K.D., et al., Asthma and the elite athlete: Summary of the International Oly pic Committee's Consensus Conference, Lausanne, Switzerland, January 22-24, 2008. Journal of Allergy and Clinical Immunology, 2008; 122(2):254-260.e7.

8. WADA The world anti-doping agency Prohibited list. 2020. 


\section{Lesões e tempo frio}

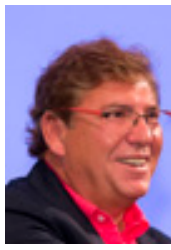

Dr. Henrique Jones

Ortopedia. Clínica Ortopédica do Montijo, Hospital da Luz Setúbal. Past-President da SPAT e da ESMA, Past Vice-presidente do Comité Médico da UEFA

As condições atmosféricas, juntamente com o equipamento desportivo, o planeamento do treino, as condições das instalações desportivas, o estilo de vida e a especificidade da atividade desportiva e modalidade praticada fazem parte dos fatores de risco extrínsecos da lesão desportiva.

Com efeito, sabemos que as baixas temperaturas contribuem para um maior número de lesões. O Comité Olímpico Internacional (IOC) e a Federação Internacional de Ski (FIS) adotaram a estratégia de desaconselhar competição com temperaturas inferiores a $-27^{\circ} \mathrm{C}$. A União Europeia de Futebol Association (UEFA) propõe o adiamento das competições se a temperatura for igual ou inferior a $-15^{\circ} \mathrm{C}$, a não ser que as equipas envolvidas e o árbitro concordem em competir.

O impacto fisiológico e metabólico do exercício a baixas temperaturas poderá ser intenso. O organismo necessita de produzir energia extra para manter um desempenho desportivo e ao mesmo tempo manter a temperatura corporal adequada. A simples compreensão deste fenómeno implica uma instalação mais precoce da fadiga e, consequentemente, a possibilidade de maior número de lesões, sobretudo musculares. A hipotermia $\left(<35^{\circ} \mathrm{C}\right)$ e a vasoconstrição periférica são fatores comuns a lesões, sobretudo cutâneas, muitas vezes severas $\left(-27^{\circ} \mathrm{C}\right)$.

Também o risco de lesão muscular, ou outro tipo de lesões musculoesqueléticas, aumenta

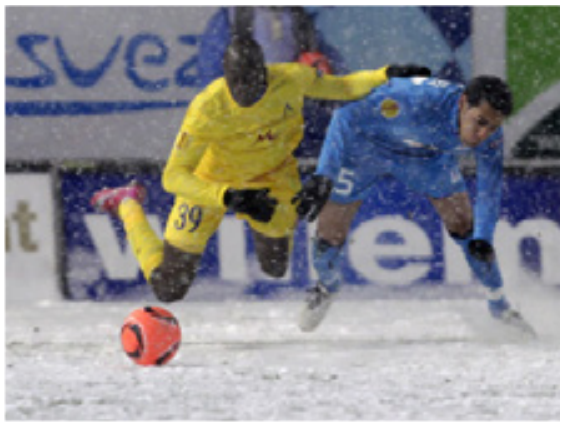

em condições de baixas temperaturas (abaixo de $0^{\circ} \mathrm{C}$ ). Com efeito, o número de lesões por trauma direto (quedas) ou feridas abrasivas e queimaduras tem maior incidência em condições climáticas da adversas, como as baixas temperaturas.

No que concerne às lesões musculares, são efetivamente mais frequentes em baixas temperaturas e é importante perceber as causas implicadas no sentido de estratégias de prevenção. O principal fator é a impreparação muscular para a participação num treino, ou competição, nas referidas condições. A manutenção do aquecimento corporal e muscular é fundamental no sentido de manter condições vasculares no músculo que permitam o desempenho desportivo. A manutenção de exercícios de preparação muscular permite condições de nutrição e vascularização que minimizam o risco de lesão muscular. A lesão surge sobretudo quando o movimento se inicia subitamente em condições em que a vasoconstrição e a isquemia muscular podem estar presentes. A ativação neuromuscular permanente é o segredo para manter circulação e temperatura nos membros, contrariando a tendência do organismo de resguardar o calor interno homeostático.

Em conclusão, no que se refere a lesões desportivas em baixas temperaturas, mais do que a importância da temperatura exterior, é o aquecimento muscular deficiente (além do equipamento adequado), o principal fator a merecer atenção nas estratégias de prevenção de lesões nestas condições particulares.

\section{Bibliografia}

1. Sallis R. Chassay C.M. Recognizing and treating common cold-induced injury in outdoor sports. Med Sci Sports Exerc. 1999; 31(10):1367-1373.

2. Cappaert, Thomas A, et al. National Athletic Trainers' Association Position Statement: Environmental Cold Injuries. Journal of Athletic Training. 2008; 43(6):640-658.

3. Keller, Cary S. Guidelines for Competition in the Cold. NFHS High School Today. July 28, 2014

4. Castellani J.W, Young A.J, Ducharme M.B, Giesbrecht G.G, Glickman E, Sallis R.E. Ame rican College of Sports Medicine position stand: prevention of cold injuries during exercise. Med Sci Sports Exerc. 2006; 38(11):2012-2029.
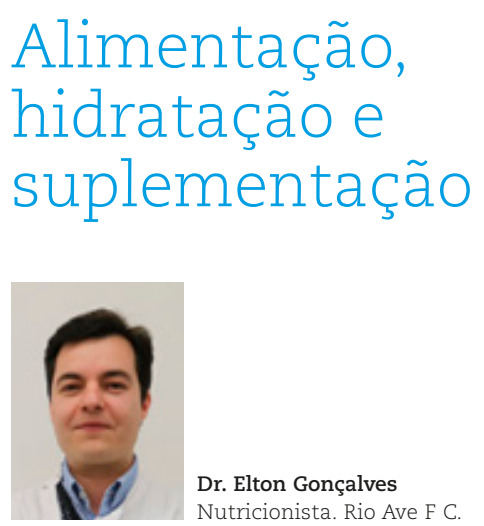

Com a chegada dos meses mais frios de inverno são esperadas condições climáticas mais adversas à prática desportiva, como aumento da precipitação, vento, humidade relativa e redução da temperatura média. Estas e outras características dos meses mais frios têm consequências no quotidiano dos atletas. Desde a menor exposição solar, provavelmente menor atividade física, um maior número de eventos festivos e sociais, e claro, uma maior prevalência de doenças infeciosas respiratórias. No entanto, as necessidades nutricionais são estáveis ao longo de todo o ano e não existem recomendações nutricionais específicas para os meses de inverno, quer para a população em geral, quer para atletas. Existe, sim, reforço das recomendações ou, se necessário, efetuar ajustes em função da situação vivida pelo atleta.

\section{Na alimentação:}

1. Ajustar a ingestão energética em função do plano de treinos, eventos competitivos e períodos de pausa do atleta, fulcral para manter uma composição corporal otimizada;

2. Reforçar a importância das frutas e vegetais, fornecedores por excelência de micronutrientes essenciais, uma vez que podem ser menos apelativos nos períodos de temperaturas mais baixas;

3. Aproveitar a sazonalidade dos alimentos, onde existem alimentos nutricionalmente mais ricos e, eventualmente, com menor pegada ecológica;

4. Minimizar o consumo de alimentos hipercalóricos e bebidas alcoólicas, tipicamente mais disponíveis durante as épocas festivas. 


\section{Na hidratação:}

Nos dias em que as temperaturas são mais baixas, a hipoidratação em atletas pode ocorrer tal como nos dias de maior calor. A menor sensação de sede (associada a menor ingestão hídrica) e a menor perceção da quantidade da transpiração por parte do atleta podem dificultar o controlo da hidratação e até potenciar estados crónicos de hipoidratação. A hipoidratação (perda de massa corporal $>2 \%$ ) afeta negativamente a performance física, técnica e cognitiva do atleta. ${ }^{1}$

Tal como acontece nos meses de verão, a monitorização do correto estado de hidratação do atleta pode ser efetuada com vários métodos, e sempre que possível a estratégica de hidratação deve ser personalizada:

1. Avaliação da primeira urina matinal (gravidade específica $\leq 1.020 \mathrm{~g} / \mathrm{ml}$ ou osmolaridade $\leq 700 \mathrm{mOsmol} / \mathrm{kg}$ );

2. Estabelecer um valor basal para a massa corporal do atleta, através de várias pesagens em dias consecutivos, que representará a massa corporal para o estado euidratado;

3. Quantificar as perdas através da transpiração durante o exercício do atleta e estabelecer um protocolo de reidratação em função do tipo e duração do exercício, bem como das características ambientais. A reposição de fluídos deverá ser $150 \%$ da massa corporal perdida durante o exercício. ${ }^{2}$

\section{No sistema imunitário:}

Uma alimentação variada, equilibrada e completa, que garanta o fornecimento adequado dos macro e dos micronutrientes, é a melhor forma de promover o correto funcionamento do sistema imunitário, para que este cumpra com as suas funções de defesa. Não obstante, alguns suplementos alimentares apresentam potencial interesse de utilização, mas ainda é necessária mais investigação. ${ }^{3}$

\section{Probióticos}

Alimentos com probióticos (leites fermentados, iogurtes, queijos) ou suplementos alimentares à base de probióticos podem potencialmente produzir uma variedade de benefícios para a saúde, incluindo a menor incidência de infeções respiratórias superiores (IRS), menor duração da doença e da sua sintomatologia. ${ }^{3,4}$ É ainda necessária mais investigação nesta área para esclarecer quais as estirpes de probióticos mais benéficas, a dose-resposta mais adequada e recomendações claras para a implementação, ou não, de suplementos probióticos na comunidade desportiva. ${ }^{5}$

\begin{tabular}{ll}
\hline Alimentos & $\begin{array}{l}\text { Teor de vitamina C } \\
\text { (ajustado para o peso edível dos alimentos) }\end{array}$ \\
\hline 2 kiwis médios $(111 \mathrm{~g}$ cada) & $130 \mathrm{mg}$ \\
\hline 1 laranja média $(162 \mathrm{~g})$ & $64 \mathrm{mg}$ \\
\hline 1/4 prato de couve galega cozida $(60 \mathrm{~g})$ & $36 \mathrm{mg}$ \\
\hline Total vitamina C & $230 \mathrm{mg}$ vitamina C \\
\hline
\end{tabular}

\begin{tabular}{lcc}
\hline Alimentos & Vitamina D (mg) & Vitamina D (UI) \\
\hline Goraz grelhado (100g) & $17 \mathrm{mg}$ & $680 \mathrm{UI}$ \\
\hline Sardinha grelhada (100g) & $11 \mathrm{mg}$ & $440 \mathrm{UI}$ \\
\hline Linguado grelhado (100g) & $10 \mathrm{mg}$ & $400 \mathrm{UI}$ \\
\hline Salmão grelhado (100g) & $9,2 \mathrm{mg}$ & $368 \mathrm{UI}$ \\
\hline Dourada grelhada (100g) & $7,9 \mathrm{mg}$ & $316 \mathrm{UI}$ \\
\hline Robalo grelhado (100g) & $6,7 \mathrm{mg}$ & $268 \mathrm{UI}$ \\
\hline Atum fresco grelhado (100g) & $4,2 \mathrm{mg}$ & $168 \mathrm{UI}$ \\
\hline Ovo (tamanho M) & $1,7 \mathrm{mg}$ & $68 \mathrm{UI}$ \\
\hline Alimentos enriquecidos com Vitamina D* & & $64 \mathrm{UI}$ \\
\hline Mimosa Leite magro c/cálcio e vitamina D (200ml) & $1,6 \mathrm{mg}$ & $60 \mathrm{UI}$ \\
\hline Danone Actimel defesas (100g) & $1,5 \mathrm{mg}$ & $60 \mathrm{UI}$ \\
\hline Alpro Bebida de soja (200ml) & $1,5 \mathrm{mg}$ & \\
\hline
\end{tabular}

*Valores obtidos na consulta de rotulagem nutricional dos produtos em outubro 2020

\section{Vitamina C}

Apesar estar enraizado na população em geral que a vitamina C ajuda a prevenir gripes e constipações, o último estudo de revisão feito pela Cochrane, concluiu que a suplementação com vitamina $C$ não reduz a incidência de infeções respiratórias superiores (IRS) na população em geral. ${ }^{6}$

Em atletas, a ingestão aumentada de 250-1000mg/dia de vitamina C, parece ter um efeito protetor na incidência, redução da duração e sintomatologia da doença. Porém, a suplementação prolongada, com doses elevadas de vitamina C (1000mg), não deve ser aconselhada por dificultar as desejadas adaptações fisiológicas promovidas pelo treino. ${ }^{7}$ Deste modo, consumos diários de 200mg de vitamina C (preferencialmente obtidos pela ingestão de alimentos) são uma excelente recomendação para atletas, devido às suas necessidades aumentadas de antioxidantes e não apresenta efeitos negativos na performance desportiva. ${ }^{8}$

A ingestão de 200mg de vitamina C através dos alimentos é possível com alguma facilidade (para o cálculo foram utilizados o livro Peso e Porção de Alimentos ${ }^{9}$ e a Tabela da Composição de Alimentos Portugueses ${ }^{10}$ :

\section{Vitamina D}

As recomendações diárias de vitamina $D$ para adultos são $15 \mathrm{mg} /$ dia (600 UI). ${ }^{11}$ De forma regular, estes valores são difíceis de alcançar exclusivamente através da ingestão de alimentos. Nos meses de inverno, onde existe menor exposição solar, a prevalência da insuficiência de vitamina $\mathrm{D}(<30 \mathrm{ng} / \mathrm{ml})$ e de deficiência de vitamina $\mathrm{D}(<2 \mathrm{nng} / \mathrm{ml})^{12}$ assumem um papel de destaque dada a importância desta vitamina para o correto funcionamento do sistema imunitário. ${ }^{13}$ Para além da ingestão de alimentos ricos em vitamina D [Tabela da Composição de Alimentos Portugueses $^{9}$ ], a suplementação em vitamina D3 éuma abordagem lógica quando os valores sérios de $25(\mathrm{OH})$ D são inferiores a 20ng/ml. Apesar de ainda não existir um consenso relativamente a atletas, a suplementação entre 2000UI - 4000UI por dia é referida como eficaz e segura. ${ }^{14}$ 
Bibliografia

1. ACSM American College of Sports Medicine. Joint Position Nutrition and Athletic Performance. Medicine \& Science in Sports \& Exercise. 2016; 48(3):543-568.

2. awka MN, Burke LM, Eichner ER, Maughan RJ, Montain SJ, Stachenfeld NS. American College of Sports Medicine position stand. Exercise and fluid replacement. Med Sci Sports Exerc. 2007 Feb; 39(2):377-90.

3. Walsh NP. Nutrition and Athlete Immune Health: New Perspectives on an Old Paradigm. Sports Med. 2019 Dec; 49(Suppl 2):153-168.

4. Hao Q, Dong BR, Wu T. Probiotics for preventing acute upper respiratory tract infections. Cochrane Database Syst Rev. 2015 Feb 3;(2):CD006895. doi: 10.1002/14651858. CD006895.pub3.

5. Pyne DB, West NP, Cox AJ, et al. Probiotics supplementation for athletes: clinical and physiological effects. Eur J Sport Sci. 2015; 15(1):63-72.

6. Hemilä H, Chalker E. Vitamin C for preventing and treating the common cold (Review). 2013; 8. The Cochrane Collaboration. Published by John Wiley \& Sons, Ltd.

7. Braakhuis, Andrea J. Effect of Vitamin C Supplements on Physical Performance. Current Sports Medicine Reports. 2012; 11(4):180-4.

8. Neubauer O, Yfanti C. Antioxidants in Athlete's Basic Nutrition: Considerations towards a Guideline for the Intake of Vitamin $C$ and Vitamin E. In: Lamprecht $M$, editor. Antioxidants in Sport Nutrition. Boca Raton (FL): CRC Press/Taylor \& Francis; 2015. Chapter 3.

9. Goios A, Martins ML, Oliveira AC, Afonso C, Amaral T. Peso e Porções de Alimentos $3^{a}$ Edição. U. Porto Editorial. Fevereiro 2020. ISBN: 9789897462122.

10. Instituto Nacional de Saúde Dr. Ricardo Jorge (INSA) Tabela da Composição de Alimentos Lisboa: INSA, 2007 Propriedade: INSA/Centro de Segurança Alimentar e Nutrição Depósito legal: 242944/06.

11. Dietary Reference Values for nutrients Summary report European Food Safety Authority (EFSA). EFSA Supporting publication 2017; e15121.

12. Direção Geral de Saúde. Norma no 004/2019 de 14/08/2019 - Prevenção e Tratamento da Deficiência de Vitamina D. URL [consultado maio 2019] Disponível em: https://www.dgs.pt/directrizes-da-dgs/ normas-e- circulares-normativas/norman-0042019-de-14082019-pdf.aspx

13. de la Puente Yagüe M, Collado Yurrita L, Ciudad Cabañas MJ, Cuadrado Cenzual MA. Role of Vitamin D in Athletes and Their Performance: Current Concepts and New Trends. Nutrients. 2020; 12(2):579.

14. Owens DJ, Allison R, Close GL. Vitamin D and the Athlete: Current Perspectives and New Challenges. Sports Med. 2018; 48(1):316.

\section{Vestuário de alta competição para frio extremo}

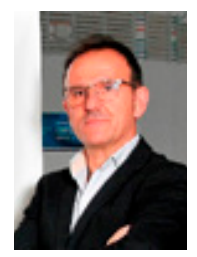

Eng. Fernando Merino Engenheiro Têxtil, Mestrado em Marketing, Especialista em têxteis técnicos e inovação. Team Leader for Transformation to Technical Textile in Denizli - Turquia.

Nos desportos de inverno o corpo tem que superar condições extremas de frio, vento forte e por vezes sol muito intenso, combinadas com atividades que induzem elevada transpiração. As marcas de vestuário de desporto, mais avançadas tecnologicamente, têm vindo a estudar o impacto das condições extremas de inverno no desporto para criarem vestuário exclusivo que associa funcionalidades e elevados padrões de desempenho. Os melhores atletas são mesmo o melhor exemplo de como o vestuário faz parte de todo o processo para a melhoria do desempenho em competição.

Os atletas de alta competição de desportos de inverno, na Noruega e na Rússia, bem como o octocampeão de Ironman, Timo Bracht, e a ciclista profissional alemã, Hanka Kupfernagel, que compete em todas as disciplinas, como ciclocross, estrada, pista e montanha, todos têm em comum o facto de usarem a tecnologia de vestuário funcional X-BIONIC $®$, a grande revolução tecnológica em vestuário de desporto, nos últimos 15 anos.

O atleta de enduro Noel Hanna, que escalou o Monte Everest seis vezes, usa X-BIONIC ${ }^{\circledR}$ e afirma que pela sua experiência, quando o risco de congelamento estava presente, e quando começava a transpirar, esta tecnologia disponibilizava um impercetível filme de humidade que arrefecia a sua pele, o que lhe permitia manter o equilíbrio de energia com eficiência, porque o corpo não despendia a energia para a regulação da temperatura corporal e depois poderia utilizá-la para a atividade motora.

O motociclista húngaro Ákos Németh, que percorreu mais de 40.000 quilômetros pela India e Nepal, usa X-BIONIC ${ }^{\circledR}$ Energy Accumulator ${ }^{\circledR}$ como roupa interior. Embora tivesse sido originalmente concebida como roupa interior para esquiadores, também é usada por muitos atletas cuja disciplina envolve competir em condições extremas, porque é igualmente confortável tanto em condições quentes e húmidas, como em zonas frias. A eficácia atribui-se à estrutura de câmaras e canais que fornecem ar para as costas e peito. Se o ar frio penetra, essas zonas isolam-se e se o corpo começa a transpirar, a humidade evapora

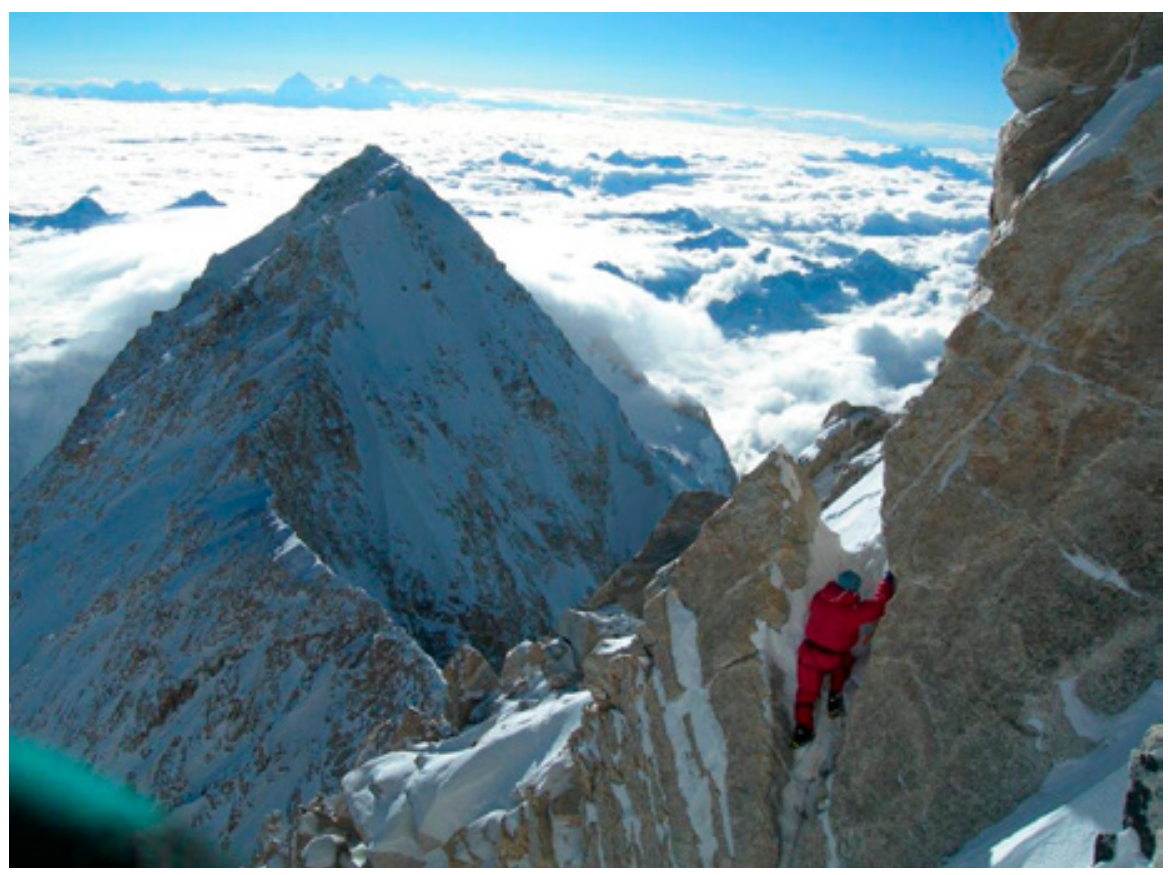

João Garcia - a caminho do cume do Kangchenjunga em 2006 
nos canais. O efeito de evaporação / resfriamento resultante funciona como o ar condicionado do corpo.

A viver em Portugal, o húngaro Bruno Hasulyo é um dos melhores atletas de SUP (Stand Up Paddle) do Mundo, campeão mundial ISA SUP em 2017 em Flat Water Long Distance, com segundos lugares em 2018 e 2019 no ISA World Championships e ICF World Championships. Embora associada ao verão, esta modalidade de surf com remo tem muitas provas em condições extremas de frio, de que é exemplo a GlaGla Race, um fenómeno do SUP que se realiza no Lago Annecy nos Alpes Franceses. GlaGla é a designação em francês para "frio de bater os dentes" porque as temperaturas em prova atingem $-7^{\circ} \mathrm{C}$, para além de se ter tornado numa das maiores provas do Mundo da modalidade, onde competiram em 2020 mais de 600 atletas provenientes de 25 nacionalidades. Entre eles os melhores atletas portugueses de SUP, nomeadamente Rui Ramos, Renato Queirós e Tomás Lacerda, este que se tornou com 17 anos no primeiro atleta português a vencer a prova no escalão júnior. Rui Ramos e Renato Queirós, por exemplo, utilizaram na prova o fato protetor SUPSKIN, da empresa austríaca que em 2017 se mudou para Portugal, para desenvolver com a indústria de têxteis técnicos portuguesa a inovação de vestuário para SUP. O SUPSKIN privilegia o alongamento e a respirabilidade para provas intensas, com tecidos que mantêm o corpo aquecido mesmo em batimentos cardíacos mais baixos, colados a uma membrana impermeável e respirável.

Os planos de treino do Bruno Hasulyo consistem em exercícios fora da água, como corrida, exercícios de força no ginásio e treinos de SUP na água. Em qualquer

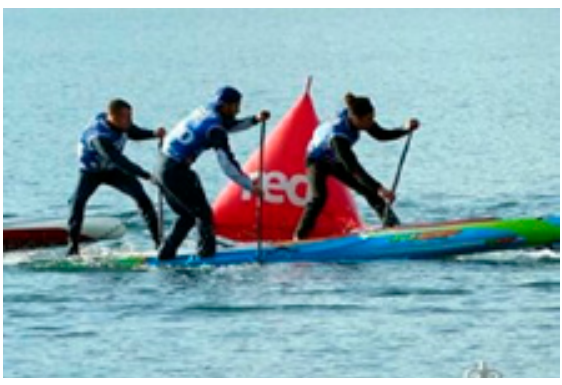

Rui Ramos e Renato Queirós na Gla Gla 2020 circunstância, mas acima de tudo na corrida e na água, quando as condições de temperatura e de vento da zona de Vila Nova de Gaia, onde vive entre o rio e o mar, são extremas, o vestuário X-BIONIC ${ }^{\circledR}$ é fundamental. O Bruno usa uma camisola com termorregulação inteligente e Partialkompression ${ }^{\circledR}$, tecnologia patenteada que melhora o arrefecimento, a frequência cardíaca, a resistência, a recuperação e a redução da acumulação de ácido lático. Usa também calção com Ideo-Waistband, o calção de corrida da nova geração X-BIONIC 4.0, em que a energia libertada pelo início precoce do resfriamento evaporativo flui diretamente para o desempenho de corrida. $O$ Partialkompression ${ }^{\circledR}$ exerce pressão suave sobre a pele por meio de barras e por isso protege da fadiga muscular prematura e, simultaneamente, mantém o importante efeito de resfriamento da transpiração. Os Iso-pads acima do osso do quadril protegem os órgãos subjacentes do frio, fornecendo isolamento direcionado com precisão. A interação entre a zona de ar condicionado Innerlap (superfície de resfriamento especial na parte interna das coxas) e o Sweat Traps auxilia o desempenho, com transporte de humidade otimizado e efeito de resfriamento. X-BIONIC ${ }^{\circledR}$ trabalha em cooperação com o Centro de Pesquisa de Bioengenharia e Ciências Motoras da Universidade de Verona para aprovar os impactos destas tecnologias.

Agora que as provas de competição estão a recomeçar, como é o caso do SUP após um período longo de paragem devido às restrições Covid 19, e que o inverno está a chegar, protejam-se da hipotermia e procurem soluções técnicas para melhorar o desempenho com o vestuário funcional.

Nota: o autor é praticante de SUP, federado, com curso de monitor.

\section{Bibliografia}

\section{Vestuário de alta competição para frio} extremo

https://www.x-bionic.com/en/stories/new effektor_beats_old_effektor_by_far https://glaglarace.com/en/the-glagla-race/ http://www.supracer.com/glagla/

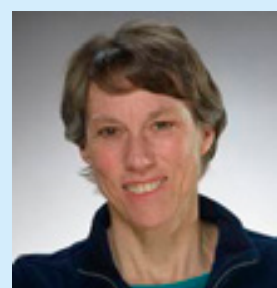

Nutricionista desportiva, 68 anos e idade e autora de quase 30 livros (EUA)

\section{Nancy Clark responde}

A comida natural pode substituir os alimentos e as bebidas artificiais ultra-processadas?

"Sim. Os alimentos naturais podem ser boas alternativas aos energéticos desportivos comerciais. Veja-se o caso das bananas! Num estudo, os atletas que consumiram bananas (para carbohidratos $(\mathrm{CH}))$ e água (para líquido) durante uma prova de ciclismo de $75 \mathrm{~km}$ tiveram o mesmo desempenho que aqueles que consumiram uma bebida desportiva (BD) com o mesmo equivalente de $\mathrm{CH}$ e água. Os alimentos naturais fornecem muito mais do que energia: contêm muitos compostos bioativos que têm um impacto positivo na saúde e no rendimento. Por exemplo, após a prova de ciclismo, os ciclistas que consumiram bananas tinham valores inferiores de oxilipinas (compostos bioativos que aumentam com inflamação excessiva) comparando com a ingestão da BD. ... Enquanto os ciclistas, em comparação com os corredores a pé, têm mais facilidade em comerem bananas durante o exercício, o saborear da banana antes da corrida fornecerá compostos bioativos ao corpo."

TriathlonWorld.com, 16 julho 2019

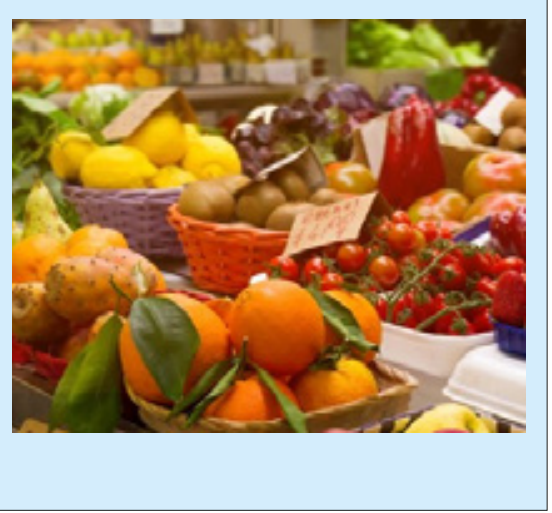

